\title{
The vulnerable insider: Navigating power, positionality and being in educational technology research ${ }^{1}$
}

Nompilo Tshuma (Centre for Higher and Adult Education, Stellenbosch University)

\begin{abstract}
This article reflects on the tensions I encountered as an insider researcher during a qualitative study exploring academics' integration of educational technology in a South African higher education institution. While critical qualitative approaches acknowledge research participants' vulnerability to the researcher's interpretation and presentation of their experiences, this article reflects on researcher vulnerability engendered by my insider status. Through a critical ethnographic lens, I reflexively interrogate the shifting nuances of power, positionality and being in educational technology research with regards to: 1) the struggle to adopt a colonialist methodology in a context still reeling from colonial legacies; 2) sensitively negotiating conflicting role requirements as a researcher, an employee and $\mathrm{PhD}$ student in the same institution; 3) reflecting on the "politics of the gaze' and how my insider status influenced what data I collected and how I perceived it; and 4) grappling with the tensions inherent in attempting to represent the experiences of the Other through my own.
\end{abstract}

Keywords: insider research, positionality, reflexivity, critical ethnography

\section{Introduction}

'We ask for revelations from others, but we reveal little or nothing of ourselves; we make others vulnerable, but we ourselves remain invulnerable' (Behar 2014)

Most qualitative educational technology research seeks to explore and capture participants' experiences and attitudes in relation to their interaction with technology for teaching and learning. As such, participants in these studies are vulnerable to the

\footnotetext{
${ }^{1}$ Pre-print article: Tshuma, N. (2021). The vulnerable insider: Navigating power, positionality and being in educational technology research. Learning, Media \& Technology, 46:2, 218229, DOI: 10.1080/17439884.2021.1867572
} 
research process, interpretations and representations of the researcher, with implications for the (mis)representation of their relation and intentions with educational technology. This vulnerability is compounded when the educational technology researcher is an insider with an intimate knowledge of the context and culture of the institution and access to personal information and covert data about the participants. In this article, I seek to extend our understanding of this vulnerability, and show how the qualitative insider researcher can potentially be vulnerable to the research process as well. As an insider researcher, I highlight the struggles and tensions that enabled my reflexive journey, and the sometimes uncomfortable shifts that occurred in my perception and conceptualisation of the research process, the participants, and their relation and interaction with educational technology.

\section{Insider research}

Starting with 'anthropological research at home' in the 1960s (Innes 2009; Merton 1972), the popularity of insider research has extended to diverse social science disciplines. In this approach, researchers seek to study organisational systems or communities where they are complete members in terms of employment status, background, religious beliefs, race, gender or language (Coghlan and Brannick 2014). The researcher therefore has some level of insider understanding of the culture or experiences of the research participants in the social context prior to the start of the research. This can potentially shape the researcher's conceptualisation of the research problem, the questions asked and the theories and research approaches adopted.

The question of the legitimacy and trustworthiness of insider research has been a contentious issue for years (Aguilar 1981; Mercer 2007). The contentions centre around issues of objectivity versus bias, detachment versus emotional closeness, culture shock versus familiarity, negotiation of access versus belonging, and the impact these issues 
have on the reliability or validity of insider versus outsider research (Innes 2009; Aguilar 1981). Other researchers argue that the insider/outsider label is a false dichotomy and should rather be viewed on a continuum as each person has different status sets which are activated at different points of the research (Mercer 2007; Merton 1972). This position posits that researchers and research participants are - to different degrees - both differentiated and similar, and thus 'typically confront one another simultaneously as Insiders and Outsiders' (Merton 1972, 22). As such, researchers have argued for nuanced understandings of the insider/outsider labels, and use terms like insider moments (May 2014), total or partial insider (Chavez 2008), indigenous or external insider (Banks 1998) and inbetweener (Milligan 2016).

Considering the above contentions of 'insider-ness', why should educational technology researchers bother with it? How will engaging with its nuances benefit their research studies? Qualitative educational technology researchers have increasingly embraced critical social inquiry approaches because of their concern with the social nature of technology and its impact on the socio-political context (Bromley 1998; Oliver 2013; Selwyn 2014). These social science approaches are premised on the notion that all social inquiry begins with self-inquiry; and that the researched can 'be understood only as part of a relationship with the self' because the self-identity of the observer 'is recreated in its relationship with the observed' (Ngwenyama 2014; Vidich and Lyman 1994, 24). Qualitative social inquiry therefore embraces researcher reflexivity, which involves 'self-disclosing' or 'positioning' ourselves in the research (Creswell 2013, 214, 216). Hence, educational technology researchers who align with a range of critical social inquiry approaches (see Dowling 2006) are compelled to be reflexive about the impact of their positionality on the research process, the participants and their research selves in order to meet the requirements of research rigour. 
Additionally, reflecting on our insider status is an acknowledgement of the political and contested nature of the research process, the technology we are researching and the context within which this technology is used. We accept that critical social research is value-driven and value-laden (Gallagher 2008) and therefore both a moral and ethical undertaking (Stahl 2008). We are also open to interrogating our (often unconscious) ideologies of technology and how these can potentially perpetuate social inequalities (Selwyn 2014; Stahl 2008). We also recognise that technology integration takes place within a context and culture, and that complex power dynamics and political agendas in this context may be further complicated by the introduction of educational technology (Bromley 1998; Friesen 2009). This makes the reflexive process a risky endeavour that exposes the vulnerability and limitations of the educational technology researcher's language and theory, culture and experiences, positionality and bias.

This paper therefore seeks to challenge educational technology researchers to be explicit about the impact of insider positionality on their research studies. A reflective narration of the tensions of insider positionality during my $\mathrm{PhD}$ research is presented in the following sections. I concur with Mercer (2007) that my presentation of these insider reflections is not an example of best practice, but rather an attempt to foster debate on an issue that is critical to the rigour of qualitative educational technology research. It is a call to researchers in the field to make themselves vulnerable by opening up to scrutiny their values, intentions and biases (Madison 2012), and how these aspects have contributed to the knowledge emanating from their research.

\section{Research context}

This paper reflects on my insider positionality during a $\mathrm{PhD}$ research study in a small South African research-intensive university. The university is the centre of a small university town which, much like the rest of the country, is disparately and visibly 
separated economically. These divisions in the town paint stark pictures of the vestiges of colonialism and apartheid. The university plays a central role in addressing various economic, social and academic concerns in the town through its engaged research, extensive community engagement and service learning initiatives as well as its engagement with the town's municipal management.

The larger PhD study that I reflect on in this paper employed a critical ethnographic methodology foregrounded by a critical realist lens. It explored academics' culture of resistance through the interplay of structure and agency, and how this culture played out in educational technology choices and practices. Data in the form of multiple in-depth interviews, observations, document analysis, informal interactions, fieldnotes and reflections were collected over 18 months between 2015 and 2017. This data documented eight academics' journeys as they encountered a range of structural forces in the academe, and how they exercised their agency to counter these forces. I was particularly interested in mapping this structural resistance to their use of educational technology (Tshuma 2018).

During this study, which was completed in 2018, I was an academic developer supporting academics in their use of educational technology in the same institution where I was registered as a doctoral candidate. Hence, I had a collegial relationship with each of the research participants prior to the start of the research. As I reflect later in this paper, various demographic attributes came to the fore during the reflective process, including my gender (female), race (black) and foreign nationality.

\section{Critical Ethnography and Reflexivity}

Critical ethnography is the approach adopted in this paper to reflect on insider positionality. Ethnography is a methodology that seeks to examine, understand and describe a social and cultural context from the point of view of the research participants 
(Harvey 1990). Because the ethnographer is attempting to portray another's culture in terms of her own, each ethnographic account is unique and is highly dependent on 'the nuances of the ethnographer's sensibility and the historical moment' in which the research takes place (Behar 2003, 20). As such, the ethnographer reinvents the methodology to some extent in order for it to align with the uniqueness of the fieldwork experience (Behar 2003).

Critical ethnography's 'critical' stance implies that it is an emancipatory methodology that interrogates and unpacks power dynamics in the research context while seeking to transform an oppressive phenomenon on behalf of (or together with) the research participants (Madison 2012; Thomas 1993). The methodology also reflexively acknowledges the power dynamics inherent in the research process (Davies 2008; Madison 2012) and the researcher's value orientations as the driving force behind research choices and practices (Carspecken 1996). For educational technology researchers, a critically reflexive approach also recognises, and potentially facilitates a critique of, ideologies and hegemonies perpetuated by the integration of technology. Selwyn (2014) elaborates on three key ideologies - libertarianism, neoliberalism and new capitalism - that underlie values and agendas in the educational technology field. While acknowledging that the existence and influence of these ideologies should be considered in the reflexive process, it is important to recognise that ideology is a highly contested term in social and political thought (Freeden 2006), as are some of the actual ideologies, in particularly neoliberalism and its origin in economic thought (Rodrik 2017; du Plessis 2010). Furthermore, researching contexts such as South Africa necessitates a consideration of how these ideologies interact with the colonial history of the country, as well as the transformation agenda that seeks to redress the still pervasive inequities (see next section). 
While I am motivating for a reflexive approach to qualitative educational technology research, I acknowledge that the actual process has been difficult and unsettling. This is because it is usually prompted by unexpected tensions, dilemmas or contradictions occurring in the field and can lead to revelations which uncover the underlying 'self' behind the written word, a self that may not align with espoused value orientations. Watson $(1987$, p. 37) terms this the "vexation of an ethnography which takes reflexivity seriously.' The researcher's authority needs to be established in order for the readers to accept the ethnography as a valid representation of the social contexts and its agents, and yet, at every turn, I as the researcher am allowing the readers to question this authority. I hope to show in the reflections below that being an insider researcher does not mean I am 'a better or worse researcher; it just makes me a different type of researcher' (Dwyer and Buckle 2009, 56), and maybe more vulnerable in some ways to the research process and context than an outsider.

The reflections discussed in the rest of this paper centre around the following themes:

- Methodological considerations - reflecting on the potential oppressive impact of what is considered an emancipatory methodology

- Multiple institutional roles - reflecting on the delicate dilemmas of my institutional roles on the research process

- Data collection - reflecting on the politics of the gaze

- Writing the research - reflecting on the tensions inherent in attempting to represent the experiences of the Other through my own.

\section{Methodological considerations}

Doing research in South Africa entails consideration of the country's lingering colonial 
and apartheid legacies. Over 25 years after independence, the country is still ranked as the most unequal in the world, a reality which permeates all parts of society, including higher education (HE) spaces (Statistics South Africa 2019). In fact, the nationwide student protests in 2015 and 2016, which saw most of the country's 26 public universities shut down for varying periods of time, were a response to this inequality and the increasing financial, academic and social marginalisation of particular groups of students and academics (Badat 2015). The use of technology in universities during these protests was often fraught with political tensions. Academics were sometimes caught between supporting student demands to completely shut down all university activities or adhering to management directives to complete the curriculum using online teaching (Czerniewicz, Trotter, and Haupt 2019). Technology also enabled student activism on social media, which served as a mobilisation tool as well as shaping news agendas and political debate (Bosch and Mutsvairo 2017). While the protests opened up discussions about the decolonisation and transformation of South African HE, there have been concerns expressed that these 'transformation discourses' - i.e., diversity and multiculturalism - are an expression of liberal ideologies and have not resulted in any real transformation taking place on the ground (Makhubela 2018). Because part of the data collection for the larger $\mathrm{PhD}$ study took place during this disruptive time, my initial reflections centred around the suitability of the critical ethnographic methodology for research in this volatile and highly unequal context.

Furthermore, for those who are educational technology researchers in the Global South, there is a need to be cognisant of the fact that the majority of the technologies used for teaching and learning at university level were developed in the Global North. As such, their cultures and hegemonies about teaching and learning 'are given durable form' in these technologies (Bromley 1998, 23), and may potentially contradict 
preferred approaches to teaching and learning in various African HE contexts. The introduction of educational technology in these contexts also reinforces any existing social inequities and thus potentially perpetuates colonialist legacies and the tension between political ideologies and the transformation agenda (Tshuma and Krauss 2017). Therefore, the methodology I selected had to provide me with the tools to interrogate these assumptions about technology, uncover political tensions perpetuated by technology and capture a contextually embedded narrative of academics' experiences with technology.

Ethnography has its roots in $15^{\text {th }}$ and $16^{\text {th }}$ century Europe, and was motivated by the desire to explain the origins and culture of newly discovered 'primitive' and racially diverse peoples who were thought to be 'less civilised' than the Westerners (Vidich and Lyman 1994,25$)$. Between the $17^{\text {th }}$ and $19^{\text {th }}$ centuries, the driving force for observing, evaluating and 'culturally advancing' these 'native' peoples shifted to colonialism (Vidich and Lyman 1994). The English, French, Spanish and Dutch used information from thick cultural descriptions to subjugate indigenous peoples in order to exploit their labour power, extract their natural resources and establish military bases (Smith 2012; Vidich and Lyman 1994). A myriad of deeply disturbing and dehumanising acts bore the name of ethnographic research, some of which have continued to impact the culture and sense of humanity of these indigenous peoples as represented in cultural stories, poems and songs (Smith 2012).

The colonial ethnographers' oppressive contact with the 'exotic, and often darkskinned "other"” (Denzin and Lincoln 2018a, 9) was perpetuated by an arrogant assumption about who could tell their stories and to whom (Behar 2003). The contact and relation of these indigenous peoples with 'civilised races' was observed and interpreted from the value orientations and prejudices of the ethnographers, thus 
presenting 'a reversed mirror image of [the ethnographers'] own ethnocultural ideal' (Erickson 2018; Smith 2012; Vidich and Lyman 1994, 26). The observed peoples had no say in how the knowledge about their culture was mined and interpreted, and often had no idea what stories were told about them and to whom. As insider researchers, we need to be particularly cognisant of the values and ideals which motivate and guide our studies, and avoid the arrogance that is described above. However, this is easier said than done as we have been accused of being stuck in an ed-tech bubble, viewing ourselves as the over-engaged technology 'elites,' and often desensitised and out of touch with the experiences of those we view as the under-engaged 'masses' (Selwyn 2012; Morozov 2011). Furthermore, as insider researchers, we assume we have an intimate understanding of the context and the research participants' experiences with technology, when our understandings could very well be a 'reversed mirror image' of our own warped ideals. These understandings are also likely clouded by political ideologies, and we run the risk of perpetuating them in the way we research and tell these technology stories.

As critical ethnographers seeking to expose and challenge oppressive power structures, we need to acknowledge that we are still focusing on 'predominantly members of socially disadvantaged groups' in our studies, a label that is coined and perpetuated by powerful social structures (Mayall, Hood, \& Oliver, 1999, p. 1). Since about the mid- $20^{\text {th }}$ century, some communities have challenged this oppressive labelling, the research done in their communities and the stories that had been told about them for centuries (Erickson 2018). This has been done through counter-stories, the development of indigenous research methodologies that embrace their culture and humanness, as well as legal action taken against ethnographers (Smith 2012; Erickson 2018; Vidich and Lyman 1994; Denzin and Lincoln 2018b). Looking at critical 
educational technology studies, the same principle pervades: selecting participants who are disadvantaged in some way. This could be because they are in resource-constrained areas where they do not have access to technology or other infrastructure (i.e., the Internet), or do not have the requisite digital literacies. This begs the question, who labels them as disadvantaged and what impact does this label have on the researcher, the researched and the presentation of the research results? Insider researchers need to be aware of the power dynamics inherent in labelling some members of the university community as disadvantaged, and how this not only perpetuates the label but also cements the status of these members in the institution (and potentially how they view themselves and their use - or non-use - of educational technology). In South Africa particularly, this label may have unintended consequences on the transformation agenda and its push to redress past inequities.

My reflections therefore centred around the above issues and whether the term 'critical ethnography' was an oxymoron, a buzzword coined for political correctness to blindside issues of inequality and social justice? Could I as a researcher claim that a methodology originally designed to oppress indigenous peoples could now be considered as a feasible option to accomplish the exact opposite in a context where the majority of the population are still reeling from the legacies of colonialism and apartheid? In what ways could my insider status potentially aggravate the political issues emanating from the foundations of this methodology, its use in the particular context of this study and the technological ideologies this engendered?

Reading and reflecting further on the methodology led to texts that convinced me that I did not have to feel incapacitated by its origins or view it as 'an act of apology and grief for the shamefulness of what ethnography was in the past' (Behar 2003, 15). Instead, the methodology could potentially align with the objectives of the larger $\mathrm{PhD}$ 
study. Firstly, the methodology could reveal the 'structural origins' (Rees and Gatenby 2014) of our (the research participants' and mine) subjective understandings of technology practices in context. Secondly, as mentioned earlier, researchers' value orientations drive research choices especially in the context of political agendas (Thomas 1993). Therefore, while acknowledging the political dynamics of doing research and the unequal power structures in society, the methodology compels the researcher to reflexively bring to light her value commitments and their impact on the research-in-context. These structural origins of our subjectivities and as well as value commitments could potentially bring to light technological ideologies underlying our understandings and how these were perpetuated in the institution.

While internal tensions initially held me back from fully embracing this methodology, reflecting on, and owning, the methodology enabled me to shift the way I thought about the research study. I came to realise that I as an academic developer - not the research participants - was the one in need of emancipation from myopic and potentially oppressive assumptions about academics' experiences with educational technology. I needed to move beyond the technology rhetoric and its utopian optimism, explore their practices in context and challenge long-held views (both mine and those in extant literature) about academics' resistance to educational technology (Tshuma 2019).

\section{Managing the delicate dilemmas of multiple institutional roles}

As an academic developer supporting the integration of educational technology, I recognised the inevitable influence on the research process engendered by my institutional role. The long-term, often close and multi-stranded relationship that I had developed with the research participants prior to and during the research (Davies 2008) sometimes exposed delicate dilemmas. I reflect below on just one of a number of dilemmas which presented both during and after the research: managing expectations. 
Managing the expectations of research participants is an issue encountered by most qualitative researchers. However, this issue is even more pertinent for insider researchers as these expectations may be intertwined with their institutional role - as was the case for my study. One of the research participants, who is a senior academic, expressed during our first interview that she was excited to take part in this research because it gave her direct access to our educational technology support office. While her comments made me a little apprehensive, I did not realise the import of her words and the demands this would place on my institutional role.

Despite my apprehensions, my $\mathrm{PhD}$ supervisor urged me to comply as this would give me access to richer observational data. Because I was located in an academic development unit offering support to academics, the boundaries appeared blurred in terms of what I was required to do in terms of educational technology support, and what I could consider as an unrealistic demand from an academic. Institutional expectations in terms of educational technology use, and the status of academics who were innovative with technology, all came to bear on my decision to assist her with her request. Over the next few weeks, I spent a considerable amount of time assisting her with educational technology requirements both in and outside class, which placed a toll on my workload and was an emotionally frustrating time for me. I did eventually manage to slowly extricate myself from what I felt had become a messy research relationship with blurred boundaries.

Reflecting on my experience with these conflicting expectations, I realised that the power dynamics in the research relationship are highly complex and difficult to define, particularly for insider researchers. I as a junior academic and $\mathrm{PhD}$ student at the time, had pressure from both my supervisor and this research participant (who were both senior academics), and had complied for the sake of my research. I also felt there 
was an expectation from the institution in terms of educational technology support which emanated from assumptions about the role of technology in the competitiveness and market share of universities (Njenga and Fourie 2010). While I strongly felt that the research demands in this instance went beyond what I required in terms of data or my institutional role, I was working under the direction of powerful Others who had an influence on the success of my $\mathrm{PhD}$ and my access to relevant data. I also had to consider the post-research relationships I would like to maintain. I keenly recognised that while the research process is actually an 'act[] of domination even as critical ethnographers reveal the same in what they study' (Noblit, Flores, \& Murillo Jr, 2004, p. 5), the insider researcher as a data collection instrument herself was also subject to domination, especially when researching powerful Others in a context influenced by political/economic ideologies. And while critical ethnography demands that the needs of research participants should come first when there is a conflict (Madison 2012), where does one draw the line? How does an insider researcher negotiate demands and expectations from a more powerful Other in such a way that the outcome does not constrain the study or post-research relationships?

My attendance in her classes over the four weeks, however, did result in positive outcomes for the research, and particularly my interpretation of her data. I was able to observe her teaching over a longer period of time than the other participants. I recorded detailed observations in terms of the different ways she employed technology in her class; how she sensitively dealt with social inequities, and in particular students who did not have access to the technology they needed in order to engage in classroom activities; and how she used technology to enable her students to access disciplinary knowledge and experts. I also observed how she handled conflicts in the class, how her students responded to her and how she managed challenging situations, and particularly 
those related to technology. These additional observations opened up new avenues of exploration during our next interview (which I did not have with the other participants), and she emotionally recounted departmental and institutional challenges she had to contend with which limited what she wanted to do in her class with technology. While I could not include the contributions of her students in my data as they were not requested to provide their consent for this research, their perspectives and experiences were invaluable in my interpretation of this research participant's context and practices. I realised that this encounter helped me understand her reaction (agency/resistance) to the intensely oppressive structural forces that she struggled with in various spheres, and how this agency/resistance was perpetuated in her integration of educational technology.

\section{Reflecting on the politics of the gaze}

Collecting data from social agents is a complex endeavour because 'there is no clear window into the inner life of an individual' (Denzin and Lincoln 2018a, 17). Furthermore, as an insider researcher I had to regularly interrogate my perceptions of the data in order to avoid what Gee (2013) terms the 'confirmation bias', where my values and biases (about educational technology, in this instance) so cloud my understanding of the data that whatever the research participants say or do in my presence only serves to confirm what I already believe to be 'truth'. Because I had known each of the research participants prior to the start of the research and had supported them in their use of educational technology, I potentially ran the risk of missing crucial data which could give me insights into their experiences in the social context and with educational technology. My proximity and experiences in the research context prior to the start of the study could mean that 'too much [was] too familiar to be noticed or to arouse the curiosity essential to research' (Aguilar 1981, 16). 
My biases during data collection often showed up unexpectedly. One example of this is that as a black woman from a different African country, I sometimes felt that my interpretation and understanding of race and blackness was dissimilar in some respects from the experiences of black South Africans. This shortfall in my understanding of the South African experience surfaced as I was grappling to comprehend the sometimes furiously vehement responses to what I considered normal (but not necessarily pleasant) conversations or actions. A case in point is a story related by one of the research participants about her experience as a university student:

I can talk about the violence I experienced in res just you know as a student. The issue of being invited in certain social functions that you didn't even know the concept you know, being told that actually we've ordered pizza hey. All of us will have to cough up ten rands. And you're like but I don't have ten rands. And you know common room is full of students. And people are like, so you don't have ten rands, what do you mean? You know that kind of violence... (R1 interview $09 / 12 / 2015)$

When she initially spoke about this incident, I felt it was a regular occurrence in contexts where there are different levels of privilege - people will sometimes make assumptions about the privilege of others based on their own. But through further interactions with the research participant in subsequent interviews, she shared with me the struggles of her working class background and the discrimination and oppression she had experienced from childhood. I began to understand the 'ordained violence' and 'denied humanity' engendered by the apartheid system, and how, consequently blacks' contributions in the academe could 'represent[] disruptions and rupture' of the status quo (Makhubela 2018, 1; Gordon 2000, 2,3). And while as a student she often did not challenge assumptions that perpetuated violence against her, as a staff member she found herself having to disrupt and rupture the status quo by challenging other 
academics to acknowledge and sensitively address issues of inequity and access.

Although I had not initially understood the import of her story and how it explained her strong agency and advocacy for students from backgrounds similar to hers, I eventually came to see that this advocacy was perpetuated in her use of educational technology as she sought to level the playing field for all students by using technology to elevate and value diverse cultures (Tshuma 2018).

This participant's experience and practice with educational technology enabled me to recognise the problematic nature of the digital natives narrative in the South African context. As a young academic herself who completed her first degree in the late 2000s, there was an expectation, when she first came to university as a student, that she had the digital literacies required for her studies. This narrative, which assumes that students are digitally literate because they have grown up with technology all around them (Prensky 2001), is particularly problematic in the South African context where there are gross social and academic inequalities that result in what Brown and Czerniewicz (2010) term 'digital apartheid'. Lack of access to technology and a widening digital divide characterise the university experience of a particular demographic of students (Brown and Czerniewicz 2010; Thinyane 2010).

Experiences like these during data collection helped me realise that shared characteristics like my blackness, gender and profession did not always mean 'an immediate bond of sisterhood' (Merriam, Johnson-Bailey, Lee, Kee, Ntseane, \& Muhamad, 2001, p. 406). Reflecting on these contradictory moments enabled me to uncover my naïve and potentially hurtful assumptions about the parts of their lives they chose to share with me, and consequently open my eyes to oppressive behaviours in my context. I had fallen into a 'common vice... of believing that my own experience has great symbolic value' (Sennett 2013, 14) in understanding the experiences of the 
research participants. I realised that, as an insider researcher, I needed to find ways to acknowledge difference between myself and the research participants, which pointed to the fluidity of my identity as an insider (Hesse-Biber and Piatelli 2012; Thomson and Gunter 2011).

\section{Reflecting on authentically representing the Other}

Finally, as the researcher I had to interrogate the narrative and literary choices I made in order to tell my research participants' stories, and particularly my conceptualisation of their educational technology choices and practices. The narratives are embedded in the social context (Myers 1997) of the research participants, which makes them complex and difficult to define. As a result, researchers tend to 'make a mess' of these representations of the 'Other' and any attempts to offer simple descriptions 'simply increases the mess' (Law 2004, 2). Additionally, researchers commonly represent the culture, identities and technology experiences of the research participants through commonalities, a process which 'conflates enormous differences [in terms] of power, culture, belief, political commitments, ethnicity [and] class' (Wasserfall 1993, 23) issues which are critical to understanding the socio-political context of a country like South Africa. Even for researchers who can tell skilfully crafted and attention-gripping stories, the process is still complicated and contentious (Madison 2012) because 'we hold the meaning of people's lives in our hands' (Bar-On 1996, 20). Research participants will likely be treated in the way they are represented, thereby giving the researcher the power to interpret and shape how the readers will conceive the social context, the educational technology culture and lived experiences of the participants. The writing up of research therefore has a 'constitutive' and 'formative' role in the lives of the research participants (Hall 1996) thereby giving the researcher the power to dictate what the culture is and, in the case of educational technology, how its use (or 
non-use) should be conceptualised and explained.

The process of reflexivity that I employed throughout the larger study was instrumental in the analysis and writing of the research stories. While I only had a glimpse of the research participants' multi-dimensional existence and interactions with technology, I was driven by the desire to be true to the values that had motivated the larger PhD research study - using a theoretically informed approach to identify oppressive structures in the research context that could inform my understanding of academics' use of educational technology. In order to bring about transformation in the context, I had to be sensitive to (and with) the stories that had been shared with me and be true to the trust that the research participants had placed on me.

My initial approach of trying to understand the data was informed by literature, and the barriers and resistance narratives that dominate explanations of academics' use (or lack thereof) of educational technology (Tshuma 2019). I therefore set out to uncover these barriers that could explain the disparities in the way the academics in the research study integrated technology. However, while each of their stories was different, the commonality was the animated passion that each of them exhibited when talking about their teaching or when engaging their students in class. This was one of the main drivers that fostered a 'changed consciousness' (Hesse-Biber and Piatelli 2012) in me about the role of educational technology in their teaching. I came to realise that their use of technology for teaching was tightly bound up with how they chose to resist the various structural forces that they encountered in the academic space. The presentation of their stories, therefore, pointed to technology as a tool they used in their resistance arsenal (Tshuma 2019).

While I could not avoid the fact that I was making meaning of their stories through my own prejudiced lenses, my desire was to present their stories in such a way 
that they would be an authentic representation (authentic from the research participants' perspective) of the moment in time that I was privy to through data collection. The final narrative below gives an example of one participant's reaction to my understanding and presentation of her data.

During one interview, a research participant opened up about deep hurt, anger and frustration with the way particular powerful members of the university had handled a case she had brought to their attention. I was taken aback by how open she was in that interview because she had been guarded in her responses during our previous interviews and avoided mentioning specific names. A few days later she sent a text message asking me to "please forward the recordings and transcriptions of the 3 interviews we have done together before you put them on your thesis" (sms message 13/10/2016). From the tone of her message, it seemed she regretted her decision to let her guard down and was worried that the information may end up in the wrong hands. I immediately assured her that I would be sending my analysed results to all participants before including them in the thesis, and I hoped this would reassure her that she could still trust me as she had trusted me during the interview.

This seemed to calm her down somewhat and I shared with her a few months later my final analysis of her narrative, and particularly my understanding of how she employed technology in her teaching. Her reaction was similar to what most of the other participants had expressed: You made me out to be a hero! I never saw myself like that! This study transformed my understanding of academics' experiences with educational technology, and enabled me to see them as heroes. While they may not all have been using technology in the way I expected, each one of them was battling difficult challenges in a volatile, highly unequal and transforming HE context, and bringing 
technology into the mix in order to do what they loved most: teach and engage students meaningfully and inspire them with a passion for their subjects.

\section{Conclusion}

The aim of this paper was to reflect on insider positionality in qualitative educational technology research by focusing on nuanced power dynamics, shifting researcher positionality and the effect of these reflections on my identity. Four reflective themes were highlighted in the study. Firstly, I reflected on the tensions emanating from employing a colonialist methodology in a context still reeling from colonialist legacies. I concluded that it could evolve into a methodology that identified the researcher - not the research participants - as the one in need of emancipation from naïve and myopic assumptions about educational technology. Secondly, I reflected on navigating the delicate dilemmas of multiple conflicting institutional roles, and the power dynamics inherent in researching the more powerful Other. Thirdly, my reflections focused on the politics of the gaze and my shifting positionality during data collection which meant that I did not always understand the import of the stories the participants shared with

me. Lastly, I was conscious of the constitutive role that my representation of their stories had, and sought to tell these stories in such a way that they would be an authentic (to the research participants) representation of the part of their lived experience that they shared with me. While the reflexive process was a difficult and sometimes painful process, it helped me interrogate unanticipated contradictions, assumptions and expectations which did not always align with my espoused values and challenged my naïve and myopic conceptions of academics' educational technology use. The reflective process also helped me uncover how political ideologies played out in the technology space, and how they interact and sometimes constrain the transformation agenda of South African HE. 
Acknowledgements: I would like to thank Prof Liezel Frick for her insightful feedback and discussion on this paper.

\section{References}

Aguilar, J. L. 1981. 'Insider Research: An Ethnography of a Debate'. In Anthropologists at Home in North America: Methods and Issues in the Study of One's Own Society, edited by Donald A. Messerschmidt, 15-26. Cambridge, UK: Cambridge University Press.

Badat, S. 2015. 'Deciphering the Meanings and Explaining the South African Higher Education Student Protests of 2015-16'. Pax Academia, no. 1 \& 2: 71-106.

Banks, J. A. 1998. 'The Lives and Values of Researchers: Implications for Educating Citizens in a Multicultural Society'. Educational Researcher 27 (7): 4-17.

Bar-On, D. 1996. 'Ethical Issues in Biographical Interviews and Analysis'. In Ethics and Process in the Narrative Study of Lives, edited by Ruthellen Josselson, 4:921. Thousand Oaks, CA: SAGE Publications.

Behar, R. 2003. 'Ethnography and the Book That Was Lost'. Ethnography 4 (1): 15-39.

Behar, R. 2014. Translated Woman: Crossing the Border with Esperanza's Story. Boston, MA: Beacon Press.

Bosch, T., and B. Mutsvairo. 2017. 'Pictures, Protests and Politics: Mapping Twitter Images during South Africa's Fees Must Fall Campaign'. African Journalism Studies 38 (2): 71-89. doi:10.1080/23743670.2017.1368869.

Bromley, H. 1998. 'How to Tell If You Really Need the Latest Technology'. Thought \& Action 14 (1): 21-28.

Brown, C., and L. Czerniewicz. 2010. 'Debunking the "Digital Native": Beyond Digital Apartheid, towards Digital Democracy'. Journal of Computer Assisted Learning 26 (5): 357-369.

Carspecken, P. F. 1996. Critical Ethnography in Educational Research: A Theoretical and Practical Guide. New York, NY: Routledge.

Chavez, C. 2008. 'Conceptualizing from the Inside: Advantages, Complications, and Demands on Insider Positionality'. The Qualitative Report 13 (3): 474-494.

Coghlan, D., and T. Brannick. 2014. Doing Action Research in Your Own Organization. 4th ed. London, UK: Sage Publications.

Creswell, J. W. 2013. Qualitative Inquiry and Research Design: Choosing among Five Approaches. 3rd ed. Los Angeles, CA: Sage Publications.

Czerniewicz, L., H. Trotter, and G. Haupt. 2019. 'Online Teaching in Response to Student Protests and Campus Shutdowns: Academics' Perspectives'. International Journal of Educational Technology in Higher Education 16 (1): 43.

Davies, C. A. 2008. Reflexive Ethnography: A Guide to Researching Selves and Others. 2nd ed. London, UK: Routledge.

Denzin, N. K., and Y. S. Lincoln. 2018a. 'Introduction: The Discipline and Practice of Qualitative Research'. In The SAGE Handbook of Qualitative Research, edited by Norman K. Denzin and Yvonna S. Lincoln, 5th ed., 1-26. Los Angeles, CA: SAGE Publications. 
Denzin, N. K., and Y. S. Lincoln. 2018b. 'Preface'. In The SAGE Handbook of Qualitative Research, edited by Norman K. Denzin and Yvonna S. Lincoln, 5th ed., ix-xx. Los Angeles, CA: SAGE Publications.

Dowling, M.. 2006. 'Approaches to Reflexivity in Qualitative Research'. Nurse Researcher 13 (3): 7-21.

du Plessis, S. A. 2010. 'How Can You Be a Christian and an Economist? The Meaning of the Accra Declaration for Today'. Faith \& Economics 56 (1_2). University of Stellenbosch: 65-79.

Dwyer, S. C., and J. L. Buckle. 2009. 'The Space between: On Being an InsiderOutsider in Qualitative Research'. International Journal of Qualitative Methods 8 (1): 54-63.

Erickson, F. 2018. 'A History of Qualitative Inquiry in Social and Educational Research'. In The SAGE Handbook of Qualitative Research, edited by Norman K. Denzin and Yvonna S. Lincoln, 5th ed., 36-65. Los Angeles, CA: SAGE Publications.

Freeden, M. 2006. 'Ideology and Political Theory'. Journal of Political Ideologies 11 (1). Routledge: 3-22.

Friesen, N. 2009. Re-Thinking e-Learning Research: Foundations, Methods, and Practices. New York, NY: Peter Lang Publishing.

Gallagher, D. J. 2008. 'Value-Free Inquiry'. In The SAGE Encyclopedia of Qualitative Research Methods, edited by Lisa Given, 911-913. Thousand Oaks, CA: SAGE Publications, Inc.

Gee, J. P. 2013. The Anti-Education Era: Creating Smarter Students through Digital Learning. New York, NY: Palgrave Macmillan.

Gordon, L. R. 2000. Existentia Africana: Understanding Africana Existential Thought. New York, NY: Routledge.

Hall, St. 1996. 'New Ethnicities'. In Stuart Hall: Critical Dialogues in Cultural Studies, edited by David Morley and Kuan-Hsing Chen, 442-451. Abingdon, UK: Routledge.

Harvey, L. 1990. Critical Social Research. Vol. 21. London, UK: Unwin Hyman.

Hesse-Biber, S. N., and D. Piatelli. 2012. 'The Feminist Practice of Holistic Reflexivity'. Edited by Sharlene N. Hesse-Biber. Handbook of Feminist Research: Theory and Praxis 2. Sage Thousand Oaks, CA: 557-582.

Innes, R. A. 2009. "Wait a Second. Who Are You Anyways?" The Insider/Outsider Debate and American Indian Studies'. American Indian Quarterly 33 (4): 440461.

Law, J. 2004. After Method: Mess in Social Science Research. Abingdon, Oxon: Routledge.

Madison, D. S. 2012. Critical Ethnography: Method, Ethics, and Performance. 2nd ed. Los Angeles, CA: Sage Publications.

Makhubela, M. 2018. "Decolonise, Don't Diversify": Discounting Diversity in the South African Academe as a Tool for Ideological Pacification'. Education as Change 22 (1). University of Johannesburg: 1-21.

May, R. A. B. 2014. 'When the Methodological Shoe Is on the Other Foot: African American Interviewer and White Interviewees'. Qualitative Sociology 37 (1): 117-136.

Mayall, B., S. Hood, and Sandy Oliver. 1999. 'Introduction'. In Critical Issues in Social Research: Power and Prejudice, edited by Suzanne Hood, Berry Mayall, and Sandy Oliver, 1-9. Buckingham, UK: Open University Press. 
Mercer, J. 2007. 'The Challenges of Insider Research in Educational Institutions: Wielding a Double-Edged Sword and Resolving Delicate Dilemmas'. Oxford Review of Education 33 (1): 1-17.

Merriam, S. B., J. Johnson-Bailey, M-Y Lee, Y. Kee, G. Ntseane, and M. Muhamad. 2001. 'Power and Positionality: Negotiating Insider/Outsider Status within and across Cultures'. International Journal of Lifelong Education 20 (5): 405-416.

Merton, R. K. 1972. 'Insiders and Outsiders: A Chapter in the Sociology of Knowledge'. American Journal of Sociology 78 (1). University of Chicago Press: 9-47.

Milligan, L. 2016. 'Insider-Outsider-Inbetweener? Researcher Positioning, Participative Methods and Cross-Cultural Educational Research'. Compare: A Journal of Comparative and International Education 46 (2). Taylor \& Francis: 235-250.

Morozov, E. 2011. 'What Do We Think about? Who Gets to Do the Thinking?' In How Is the Internet Changing the Way You Think? The Net's Impact on Our Minds and Future, edited by John Brockman, 228-231. London, UK: Atlantic Books.

Myers, M. D. 1997. 'Critical Ethnography in Information Systems'. In Information Systems and Qualitative Research: Proceedings of the IFIP TC8 WG 8.2 International Conference on Information Systems and Qualitative Research, 31st May-3rd June 1997, edited by Allen S. Lee, Jonathan Liebenau, and Janice I. DeGross, 276-300. Philadelphia, PA: Springer.

Ngwenyama, O. 2014. 'Logical Foundations of Social Science Research'. In Advances in Research Methods for Information Systems Research, edited by KwekuMuata Osei-Bryson and Ojelanki Ngwenyama, 7-13. Integrated Series in Information Systems. Boston, MA: Springer.

Njenga, J. K., and L. C. H. Fourie. 2010. 'The Myths about E-Learning in Higher Education'. British Journal of Educational Technology 41 (2): 199-212.

Noblit, G. W., S. Y. Flores, and E. G. Murillo Jr. 2004. 'Postcritical Ethnography: An Introduction'. In Postcritical Ethnography: Reinscribing Critique, edited by George W. Noblit, Susana Y. Flores, and Enrique G. Murillo Jr, 1-45. New York, NY: Hampton Press.

Oliver, M. 2013. 'Learning Technology: Theorising the Tools We Study'. British Journal of Educational Technology 44 (1): 31-43.

Prensky, M. 2001. 'Digital Natives, Digital Immigrants'. On the Horizon 9 (5). Bradford.

Rees, C., and M. Gatenby. 2014. 'Critical Realism and Ethnography'. In Studying Organizations Using Critical Realism: A Practical Guide, edited by Paul K Edwards, Joe O’Mahoney, and Steve Vincent, 132-147. Oxford, UK: Oxford University Press.

Rodrik, D. 2017. 'Rescuing Economics from Neoliberalism'. Boston Review 6: 6-10.

Selwyn, N. 2012. 'Bursting out of the "Ed-Tech" Bubble'. Learning, Media and Technology 37 (4): 331-334.

Selwyn, N. 2014. Distrusting Educational Technology: Critical Questions for Changing Times. New York, NY: Routledge.

Sennett, R. 2013. Together: The Rituals, Pleasures and Politics of Cooperation. New Haven: Yale University Press.

Smith, L. T. 2012. Decolonizing Methodologies: Research and Indigenous Peoples. 2nd ed. London, UK: Zed Books.

Stahl, B. C. 2008. Information Systems: Critical Perspectives. London: Routledge. 
Statistics South Africa. 2019. Inequality Trends in South Africa: A Multidimensional Diagnostic of Inequality. Pretoria: Statistics South Africa. http://www.statssa.gov.za/?page_id=1854.

Thinyane, H. 2010. 'Are Digital Natives a World-Wide Phenomenon? An Investigation into South African First Year Students' Use and Experience with Technology'. Computers \& Education 55 (1): 406-414.

Thomas, J. 1993. Doing Critical Ethnography. Newbury Park, CA: SAGE Publications. Thomson, P., and H. Gunter. 2011. 'Inside, Outside, Upside down: The Fluidity of Academic Researcher 'Identity'in Working with/in School'. International Journal of Research \& Method in Education 34 (1). Taylor \& Francis: 17-30.

Tshuma, Nompilo. 2018. 'A Critical Realist Exploration of the Culture of Resistance in Educational Technology Integration Practices in a South African University'. Grahamstown: Rhodes University. https://bit.ly/3aMQU2Z.

Tshuma, Nompilo. 2019. " "I've Got a Deep, Complicated Relationship with Technology": Towards an Understanding of the Interplay of Barriers and Agency in Academics' Educational Technology Practices'. In Re-Imagining Curriculum: Spaces for Disruption, edited by Lynn Quinn, 217-233. Cape Town: African SunMedia.

Tshuma, Nompilo, and Kirstin EM Krauss. 2017. 'Towards Using Critical Reflection to Interrogate the Oppressive Effects of Educational Technology Use in South African Higher Education.' In . University of Cape Town, Cape Town.

Vidich, A. J., and S. M. Lyman. 1994. 'Qualitative Methods: Their History in Sociology and Anthropology'. In Handbook of Qualitative Research, edited by Norman K. Denzin and Yvonna S. Lincoln, 23-44. Thousand Oaks, CA: Sage Publications.

Wasserfall, R. 1993. 'Reflexivity, Feminism and Difference'. Qualitative Sociology 16 (1): $23-41$.

Watson, G. 1987. 'Make Me Reflexive, but Not yet: Strategies for Managing Essential Reflexivity in Ethnographic Discourse'. Journal of Anthropological Research 43 (1): 29-41. 